\title{
Research on Mid-term Review System of PPP Project
}

\author{
Jinchan Liu ${ }^{1}$, Yubo Guo ${ }^{2}$ and Chuan Chen $^{3 *}$ \\ ${ }^{1}$ Business School, Sichuan University, Chengdu, Sichuan, 610065, People's Republic of China \\ ${ }^{2}$ Business School, Sichuan University, Chengdu, Sichuan, 610065, People's Republic of China
}

\begin{abstract}
The mid-term review is a necessary window for the PPP project to move forward objectively, and it is also a tool to adjust the expected goals of all parties to the project. This paper built a mid-term review system for PPP projects based on the whole-of-life cycle, studied the objectives, content and evaluation procedures of the mid-term review of PPP projects, and took the urban and rural water supply and drainage integrated PPP project in Mianzhu city, Sichuan Province as the case for field research and interviews, to verify the feasibility of the review system. The research results have a certain guiding role for the mid-term review of PPP projects.
\end{abstract}

\section{Introduction}

PPP is called "public-private partnership" in China. It refers to a public-private partnership model in which the public authority and the private sector establish a cooperative relationship to provide public products or services. A large number of studies have shown that PPP has become the most important trend in global public utilities[1]. At present, China has become the world's largest PPP market. According to the statistics of the national PPP comprehensive information platform, since 2014 , as of July 2020, a total of 9,668 projects have been entered into the database, with an investment of 15.0 trillion yuan; a total of 6,626 signed projects have been signed, with an investment of 10.4 trillion yuan, and a landing rate of $68.5 \%$.Document No. 113 issued by the Ministry of Finance in 2014 proposed for the first time that PPP projects should implement mid-term review, and the assessment cycle is specified as 3-5 years. The latest document No. 13 issued in 2020 emphasizes again: the performance evaluation should be carried out at least once a year during the project operation period, and the annual performance evaluation should be combined every 3-5 years A mid-term review of the project should be carried out according to the situation; a post-evaluation should be carried out after the transfer is completed. It has been more than six years since the implementation of the PPP model, which indicates that a large number of PPP projects will undergo mid-term review. And starting in 2018, PPP projects will enter a period of standardized management adjustment. Taking the mid-term review as an opportunity, a large number of PPP projects will be evaluated and rectified. Therefore, build a mid-term review system for PPP projects. After each period of operation of the project, the operation status of the project will be fully grasped through mid-term review, and problems existing in the project will be discovered in time, and reasonable adjustments and corrections will be made to standardize the full life cycle management of PPP projects. It is particularly necessary to work and improve the quality of public service supply.

At present, there are still a certain degree of deficiencies in the relevant research on the evaluation and evaluation of PPP projects. In order to evaluate the performance of PPP projects, Liu and Love critically reviewed relevant studies and found that even in countries with mature PPP systems, the implementation of many PPP projects has not been fully monitored or evaluated, resulting in different industries Problems occurred in the delivery of PPP projects[2].The difficulties encountered in evaluating the performance of PPP projects are understandable, because the implementation of PPP projects is complex and involves multiple stakeholders. These stakeholders have significant conflicts of interest and involve various stages, which have different characteristics and Mission[3]. In response to this complexity, some recent studies in the PPP field have proposed a variety of evaluation perspectives, including a stage (life-cycle)-based perspective, and a stakeholder and process-based perspective [4-7]. On the whole, although with the maturity of the PPP model, there are relatively few in-depth and systematic studies on the phased assessment of PPP projects. The existing domestic research results are not strong in guidance and practicality, and incomplete coverage., Analysis of problems such as insufficient depth and breadth. Therefore, this article will combine relevant policy documents, literature and interviews with experts with practical experience to study the mid-term review system of the PPP project and the problems in practice.

\footnotetext{
*Corresponding author's e-mail: chenchuan@scu.edu.cn
} 


\section{Materials and Methods}

\subsection{Desktop research}

This paper reviewed the literature related to PPP performance evaluation and mid-term review in the field of PPP model, combined with the requirements of the research content involved, and determined the theoretical basis of this research. Through the research and application of these theories, frameworks and models, combined with case studies, the main objectives and content of the mid-term review of the PPP project are determined.

\subsection{Expert interview}

In order to achieve the collection of PPP project performance factors and data, the collection process starts with theoretical desktop research. However, the existing literature lacks complete data that meets the actual situation, so it cannot be completed only through literature review. In this case, researchers in the past often used qualitative interviews to seek information related to the research topic from experts, thereby extracting an initial list of relevant elements and data. This article uses a semistructured format to interview a number of industry experts who have more than 10 years of experience and are familiar with PPP projects. The interviewees were senior professionals from four types of organizations, namely, government agencies (including their market agencies), social sector, PPP consulting agencies, and PPP academic institutions. The implementation plan and content of the mid-term review of the PPP project were determined through recording and text recording, combined with text analysis technology.

\subsection{Case study}

Case study is a research method suitable for solving research problems such as "What", "Why", and "How" [8]. Generally, comparative case studies or multiple case studies will be considered as a more robust method [9], but this article chooses a single case, namely, the PPP project of integrated urban and rural water supply and drainage in Mianzhu City, Sichuan Province for analysis to verify the mid-term review system of the PPP project The reasons for the feasibility of the PPP project are as follows: (1) This article aims to establish a mid-term assessment framework for the implementation of the PPP project. Therefore, it is best to choose the PPP project that is in the implementation stage as a case, and the project is in the implementation stage; The project is a national-level demonstration project, and its operation mode is TOT $+\mathrm{BOT}+\mathrm{ROT}$, which is very representative; (3) Using a single typical project as a case to obtain knowledge is also a common research method in the PPP field [10].

This paper selects the PPP project of integration of urban and rural water supply and drainage in Mianzhu City, Sichuan Province for analysis to verify the rationality of the design of the mid-term review system for the PPP project. The current total investment of the Mianzhu CityRural Integrated Water Supply and Drainage PPP project is about 565 million yuan. The concession period of the project is 30 years and the construction period is 3-4 years. The project operation method is TOT $+\mathrm{BOT}+\mathrm{ROT}$. The project return mechanism is the feasibility gap subsidy. The project transaction structure is shown in Figure 1.

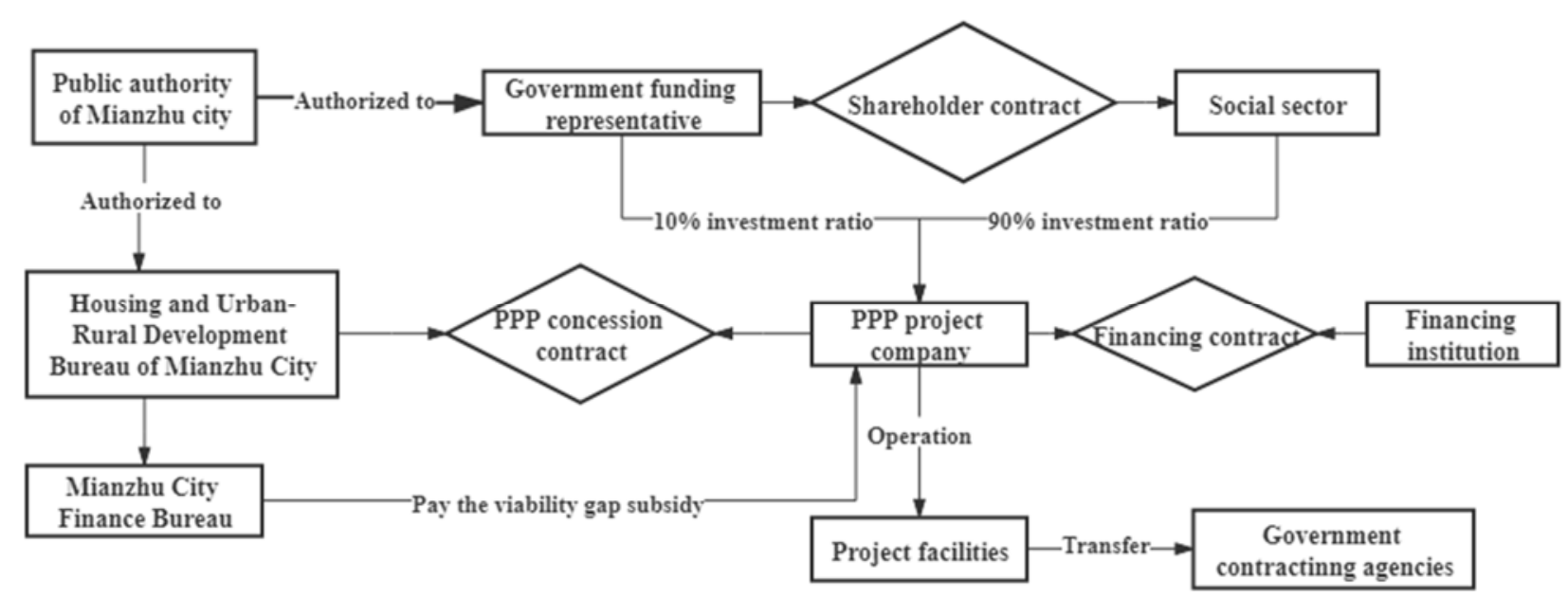

Figure 1. Project transaction structure diagram.

First, interviews were conducted with relevant managers of the government and social sector of the Mianzhu City's Urban-Rural Water Supply and Drainage Integration PPP Project. The system's evaluation content was increased, decreased, and revised based on theory and practice, and then the mid-term review process was compared with the current performance of the project. The evaluation procedures are compared and analyzed to determine the feasibility of the evaluation system.

\section{Results \& Discussion}

\subsection{Proposed PPP project mid-term review system}

Based on desktop research and expert interviews, the midterm review system of the PPP project mainly includes 
four aspects: determining the objectives of the mid-term review, the content of the mid-term review, analyzing the evaluation results, and putting forward correction suggestions. The PPP project mid-term review system is shown in Figure 2.

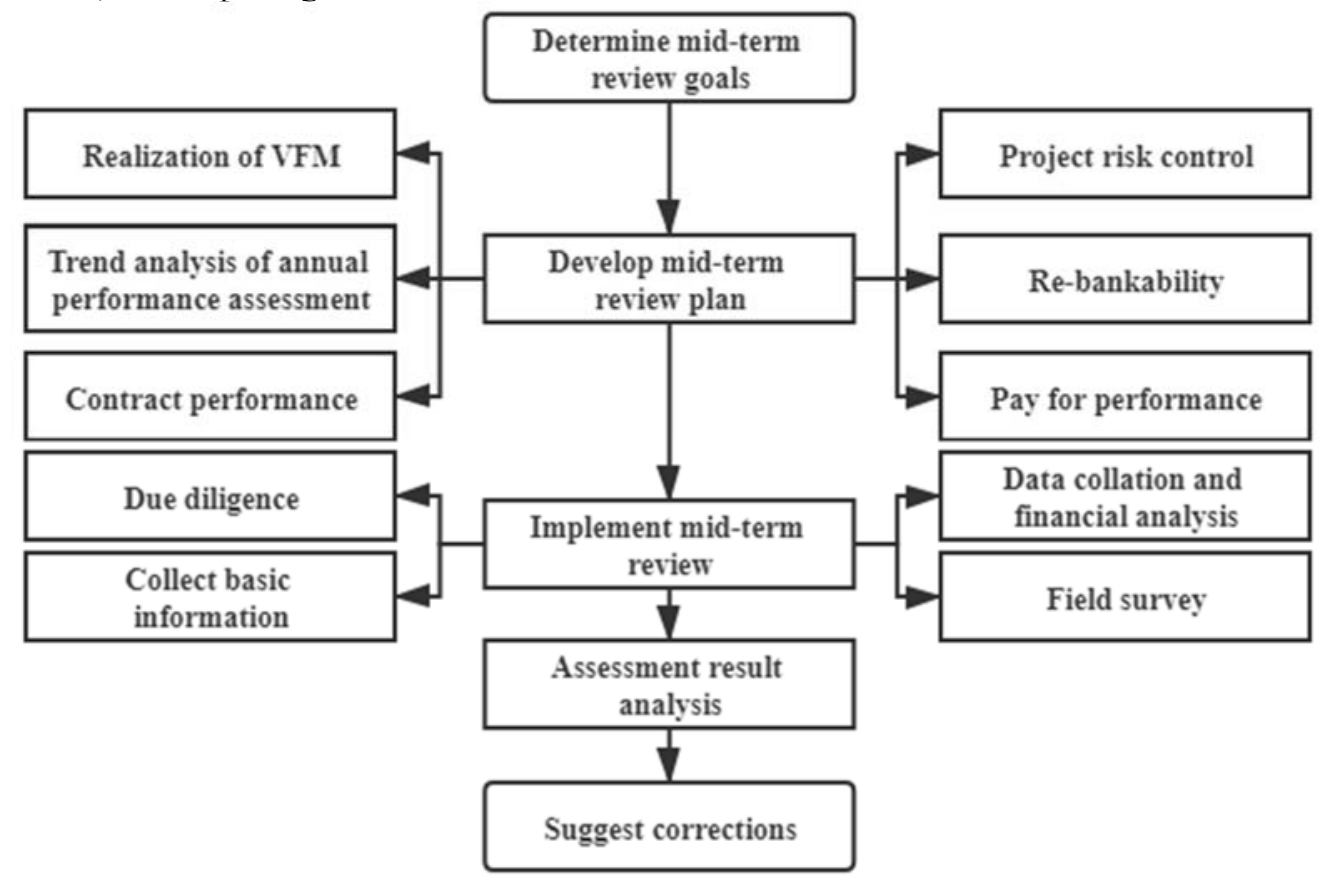

Figure 2. PPP project mid-term review system.

\subsubsection{The objectives.}

Since the cooperation period of PPP projects is at least 10 years, in practice it is usually 20-30 years, and the implementation phase has a large time span. Therefore, at a certain stage, it is likely that project operation management, government supervision, PPP project contracts, etc. are not suitable for the current The economic and technical conditions or the policy and legal environment have caused deviations in project performance goals, leading to deviations from the healthy operation of the project, and ultimately difficult to reverse the situation. The goal of the PPP mid-term assessment is to conduct a comprehensive and systematic analysis of the implementation process and effects of the PPP project that has entered the implementation stage, the realization of value for money, the realization of performance goals, the risk management of PPP projects, and the improvement of the government regulatory system. Analyze and analyze the trend of annual performance in the past period of time, put forward the content of next target adjustment and rationalization suggestions, and promote the implementation of performance targets and the sustainable development of the project.

\subsubsection{The contents.}

Based on the theoretical framework of the mid-term review of the above PPP project and combined with the case analysis of the PPP project, this article proposes that the content of the mid-term review of the PPP project mainly includes confirming the realization of value for money, evaluating the trend of annual performance appraisal, evaluating the performance of the project contract, and evaluating the project Risk management and control, assessing the feasibility of project refinancing, and assessing the implementation of pay-for-performance.

\subsubsection{Correction suggestions.}

After evaluating the above-mentioned related content, summarize the project implementation and analyze the reasons, and propose improvement measures and suggestions for the main problems. In the abovementioned PPP mid-term assessment system, the core link is the implementation of the PPP mid-term assessment. The following will focus on the analysis of the key contents of the PPP mid-term assessment.

\subsection{Discussion on the content}

\subsubsection{Confirm the realization of VFM.}

According to relevant documents of the Ministry of Finance, PPP projects should be evaluated for value for money in the identification and preparation stage. Value for money evaluation includes qualitative evaluation and quantitative evaluation, of which qualitative evaluation is the main one, and quantitative evaluation is encouraged. The reason is that in the project identification and preparation stage, the data based on qualitative evaluation is insufficient, such as construction and operating costs The basic calculations are based on various assumptions, which have strong attributes. In the mid-term review stage, since the project has been in operation for a period of time, the data support for calculating the PPP value and PSC 
value is relatively substantial and reliable. Therefore, in the mid-term review, the value for money should be reevaluated, and quantitative evaluation should be the focus, Mainly qualitative evaluation.

\subsubsection{Trend analysis of annual performance evaluation.}

According to the PPP project performance management operation guidelines, the project company (the social capital party) carries out the daily performance monitoring of the PPP project, and regularly reports the monitoring results in accordance with the requirements of the project implementing agency. Therefore, the mid-term review should be based on the project company's performance monitoring results to evaluate whether there has been a trend in performance evaluation in the past 3-5 years. That is, on the basis of the annual performance appraisal results of the past 3-5 years, a systematic trend analysis is carried out to explore the trend formed by the annual performance. If it is a positive trend, it should continue to advance; if it is a bad trend, it should be corrected and rectified.

\subsubsection{Performance of contract.}

In the mid-term review stage, it is necessary to evaluate whether the project is in accordance with the output description or bidding commitments, to ensure that the construction and operation and maintenance of the project facilities meet the agreed technical specifications and technical requirements. At the same time, the PPP project contract should be evaluated based on the actual operation of the previous stage. Adaptability and rationality. This assessment should focus on two aspects: First, according to the differences in the policy, law, and economic environment at the two time points when the project is bidding and the relevant agreement is signed during the assessment, appropriate factors in the contract that affect the operation of the project are carried out. Secondly, to dynamically adjust the relevant clauses according to the actual conditions of the project according to the actual implementation of the parties to the contract and to meet the prerequisites of the revision of the project agreement, so that the contract clauses are more closely related to the implementation and operation of the project, thereby promoting a better project To achieve its expected results.

\subsubsection{Risk review and outlook.}

Risk assessment is actually a prediction of what will happen in the future based on the information at the time. Because risk and information are relative, as the project progresses, the internal and external environments are changing, so the identification and assessment of risks should be Make real-time adjustments. Therefore, in the mid-term assessment, a new risk identification, risk assessment, and risk response should be carried out based on the actual situation.

\subsubsection{Rebankability analysis.}

Rebankability analysis is actually a reassessment of changes in the external financing environment. For example, the financial environment has changed. In the past, the financing cost of PPP projects may have been relatively high. Now due to the global economic downturn, the financing cost may be getting lower and lower. Then in the mid-term review, you can consider whether it is necessary to evaluate or predict. The feasibility and necessity of financing.

\subsubsection{Implementation of pay-for-performance.}

According to Circular 13, the government pays and the feasibility gap subsidy project, the government's annual operating subsidy expenditure should be fully linked to the project company (social capital) performance evaluation results of the year. The financial department shall arrange corresponding expenditures in accordance with the results of the performance evaluation, and the project implementing agency shall make timely payments in accordance with the project contract. Therefore, the midterm review should check the payment status of each period during the evaluation period, evaluate whether each payment actually evaluates the project output performance, and determine the payment amount according to the performance evaluation system.

\section{Conclusions}

By reviewing policy documents and literature related to PPP performance evaluation and mid-term review in the field of PPP, this paper clarifies the objectives and content of mid-term review of PPP projects, constructs mid-term review system of PPP projects, and verifies PPP by combining case studies and expert interviews The midterm review system content indicators and the rationality and feasibility of the plan. The research has certain practical significance. For the project company, the midterm assessment will help to grasp the consistency between the degree of achievement of the phased goals and the expected results, and optimize the arrangement of follow-up measures in a timely manner. For the government, the mid-term review will help it fully grasp the project company's business operations and government supervision and its existing problems, and fully understand the project's planning and implementation, engineering construction, funding arrangements, system construction, safe operation management, and public The implementation status of product supply efficiency, product and service quality, contract performance and performance evaluation, etc. is to improve the government supervision system, standardize and implement PPP project contracts, protect public interests, and better promote the healthy development of public undertakings. In addition, through mid-term review, a rolling mechanism for analyzing problems in stages and summarizing experience can be formed during the implementation of PPP projects, which is conducive to the transition between annual performance 
monitoring and post-project evaluation, and maintains the continuity of performance management at all stages of PPP projects And consistency.

\section{References}

1. Garvin, M. J., and Bosso, D. (2008) Assessing the Effectiveness of Infrastructure Public-Private Partnership Programs and Projects. Public Works Management \& Policy, 13(13): 162-178.

2. Liu, J., Love, P. E. D., Smith, J., Regan, M., Palaneeswaran, E. (2015) Review of performance measurement: implications for public-private partnerships. Built Environment Project \& Asset Management, 5(1):35-51.

3. EIB, The guide to guidance: How to prepare, procure and deliver PPP projects. (2012) European Investment Bank: Luxembourg.

4. Liu, J., Love, P. E. D., Smith, J., Matthews, J., \& Sing, C. P. (2016) Praxis of performance measurement in public-private partnerships: moving beyond the iron triangle. Journal of Management in Engineering, 32(4):04016004.1-04016004.10.

5. Liu, J., Love, P. E. D., Davis, P. R., Smith, J., \& Regan, M. (2015) Conceptual framework for the performance measurement of public-private partnerships. Journal of Infrastructure Systems, 21(1): 04014023.1-04014023.15.

6. Liyanage, C., Villalba-Romero, F. (2015) Measuring success of PPP transport projects: a cross-case analysis of toll roads. Transport Reviews, 35(2):140161.

7. Yuan, J, Zeng, Alex Y., Skibniewski, Miroslaw J., Li, Q. (2009). Selection of performance objectives and key performance indicators in public-private partnership projects to achieve value for money. Construction Management \& Economics, 27(3):253270.

8. Yin, R.K. (2014) Case study research: design and methods. Thousand Oaks, Calif.: SAGE.

9. Osei-Kyei, R. and A.P.C. Chan. (2015) Review of studies on the Critical Success Factors for PublicPrivate Partnership (PPP) projects from 1990 to 2013. International Journal of Project Management, 33(6):1335-1346.

10. Cheung, E., A.P. Chan. (2009) Is BOT the best financing model to procure infrastructure projects? A case study of the Hong Kong-Zhuhai-Macau Bridge. Journal of Property Investment \& Finance, 27(3): 290-302. 